\title{
A PROTEÇÃO DO DIREITO À MORADIA ADEQUADA E SUA IMPORTÂNCIA PARA O DESENVOLVIMENTO INFANTOJUVENIL NA PERSPECTIVA DOS DIREITOS DE PERSONALIDADE
}

\author{
Fernando de Brito Alves* \\ Ana Paula Meda**
}

SUMÁRIO: Introdução; 2 Mais que uma casa: sobre o direito à moradia adequada; 3 Ser criança e adolescente; 4 Direitos de personalidade em relação ao direito à moradia: a observação de reflexos no desenvolvimento infantojuvenil; 5 Considerações finais; Referências.

RESUMO: Os direitos de personalidade são basilares na concretização da dignidade humana, pois ensejam a realização das potencialidades pessoais. Contudo, são direitos que prescindem, no estudo em análise, da efetivação do direito à moradia adequada com interferência no desenvolvimento infantojuvenil. Estudos até então realizados nesta área relacionam o direito à moradia com os direitos de personalidade, mas não o fazem direcionados para a verificação do Estatuto da Criança e do Adolescente (ECA) em simbiose com o conceito de moradia adequada. Propõe-se um estudo acerca de como o direito à moradia é concebido no referido Estatuto e de quais maneiras a inefetividade do direito de morar reflete a violação dos direitos de personalidade e, adiante, no saudável crescimento de infantes e juvenis. Utiliza-se o método dedutivo, a fim de que a premissa da moradia adequada seja investigada em meio aos direitos de personalidade e da realização humana a partir do público infantojuvenil. A moradia é direito implicitamente reconhecido pelo ECA, de maneira que sua execução completa tende a proteger o direito à vida, à saúde, à intimidade, à integridade pessoal e à liberdade.

PALAVRAS-CHAVE: Pessoa; Vida digna; Direito de morar adequadamente; Direitos de personalidade; Crianças e adolescentes.

\section{THE RIGHT OF PROPER HOUSING AND ITS IMPORTANCE FOR CHILDREN'S DEVELOPMENT, WITHIN THE PERSPECTIVE OF THE PERSON'S RIGHTS}

ABSTRACT: The rights of the person are crucial for human dignity since they enhance people's abilities. However, they overlook the right to a proper home and subsequent interference in children 's and adolescents' development. Studies

\footnotetext{
Advogado. Pós-doutorado pelo Ius Gentium Conimbrigae da Faculdade de Direito da Universidade de Coimbra; Coordenador no Programa de Pós-graduação (Mestrado e Doutorado) em Ciência Jurídica, Brasil.

* Mestre em Ciência Jurídica pela UENP. Advogada do Núcleo de Estudos e Defesa dos Direitos da Infância e Juventude (NEDDIJ/UENP), Brasil. E-mail: anapaula.meda@yahoo.com.br
} 
have linked the right to a home to the rights of the person, but failed to focus on the Child and Adolescent Statute with regard to the concept of a proper home. Current analysis investigates the right to a home within the Statute and the ways the ineffectiveness of the right of a home represents a violation of the rights of the person and in the healthy growth of children and adolescents. The deductive method is employed so that the home premise may be investigated within the rights of the person and human fulfillment. Home is a right implicitly acknowledged by the Child and Adolescent Statute. Its full achievement protects the right to life, health, intimacy, personal integrity and freedom.

KEY WORDS: Person; Dignified living; The right to live adequately; Person 's rights; Children and adolescents.

\section{LA PROTECCIÓN DEL DERECHO A LA VIVIENDA ADECUADA Y SU IMPORTANCIA PARA EL DESARROLLO INFANTO JUVENIL EN LA PERSPECTIVA DE LOS DERECHOS DE LA PERSONALIDAD}

RESUMÉN: Los derechos de la personalidad son básicos en la concretización de la dignidad humana, pues permiten la realización de las potencialdiades personales. Todavía, son derechos que prescinden, en el estudio en análisis, de la efectivación del derecho a la vivienda adecuada con interferencia en el desarrollo infanto juvenil. Estudios hasta el momento realizados en esta área relacionan el derecho a la vivienda con los derechos de personalidad, pero no lo hacen direccionados para la verificación del Estatuto del Niño y del Adolescente (ENA) en simbiosis con el concepto de vivienda adecuada. Se propone un estudio sobre como el derecho a la vivienda es concebido en este Estatuto y de que manera la inefectividad del derecho a la vivienda refleje la violación de los derechos de personalidad y, adelante, en el saludable crescimiento de los infates y jovenes. Se utiliza el método dedutivo, para que la premisa de la vivienda adecuada sea investigada en medio a los derechos de personalidad y de la realización humana a partir del público infanto juvenil. La vivienda es derecho implicitamente reconocido por el ENA, de manera que su ejecución completa objetiva proteger el derecho a la vida, a la salud, a la intimidad, a la integridad personal y a la libertad.

PALABRAS-CLAVE: Persona; Vida digna; Derecho a vivir adecuadamente; Derechos de personalidad; Niños y adolescentes. 


\section{INTRODUÇÃO}

O estudo em questão destacou o direito fundamental social à moradia, especificamente em relação ao conceito de moradia adequada e sua influência no âmbito do desenvolvimento infantojuvenil, a partir da análise inter-relacional com determinados direitos de personalidade, quais sejam, direito à vida, à saúde, à intimidade, à integridade pessoal e à liberdade.

Este objeto de estudo tem por justificativa e relevância social o entendimento acerca da interdependência entre a proteção do direito à moradia adequada para a consequente efetivação dos direitos preconizados no Estatuto da Criança e do Adolescente (ECA), com abordagem direcionada para os direitos de personalidade já mencionados.

Diante disso, a problemática trabalhada reside na seguinte indagação: como a inadequação das moradias afeta o desenvolvimento infantojuvenil, essencialmente no que tange aos direitos de personalidade?

$\mathrm{Na}$ esteira de tal pensamento, o objetivo trazido a lume foi justamente apontar que a ausência de proteção do direito à moradia adequada reflete uma forma de violação aos direitos fundamentais das crianças e adolescentes que podem ser observados pelos direitos de personalidade.

A partir da problematização criada também foi possível pesquisar como o termo "moradia" aparece no ECA, tanto no formato literal quanto ao conteúdo trazido pela norma ao utilizar referida expressão.

Para que fosse viável o entendimento do problema suscitado tornou-se necessária a delimitação de seu estudo orientado inicialmente pela apresentação do conceito de moradia adequada com base no Comentário Geral $\mathrm{n}^{\mathrm{o}} 4$ Sobre o Direito à Moradia Adequada do Comitê de Direitos Econômicos, Sociais e Culturais da ONU (Organização das Nações Unidas) em interpretação ao Pidesc (Pacto Internacional de Direitos Econômicos, Sociais e Culturais).

Definido o conceito de moradia na ótica deste estudo, passou-se a analisar o ECA em conjunto com uma análise interdisciplinar voltada para a antropologia, considerando a criação da concepção de infância e da ideia de criança a partir de contextos socioculturais e históricos, o que intenta facilitar a compreensão da existência do próprio Estatuto em apreço.

Seguidamente, tratou-se dos direitos à vida, à saúde, à intimidade, à integridade pessoal e à liberdade em correlação com o direito à moradia, a perscrutar 
a forma pela qual a inefetividade do direito à moradia em um dos seus componentes é impactante na violação dos direitos de crianças e adolescentes, principalmente quanto aos direitos de personalidade.

Perante mencionado contexto, o referencial teórico adotado partiu da verificação do direito à moradia com base na definição contida no Comentário Geral $\mathrm{n}^{\mathrm{O}} 4$ sobre o direito à moradia adequada, adentrando uma breve análise de artigos do ECA afetos à temática proposta com multidisciplinaridade entre a ciência jurídica, a antropologia e a psicologia ambiental.

Do ponto de vista jurídico, o trabalho contou com o aporte teórico desenvolvido por Sérgio Iglesias Nunes de Souza, com relação às interfaces entre $\mathrm{o}$ direito à moradia $\mathrm{e}$ os direitos de personalidade. Quanto à visão antropológica utilizou-se, essencialmente, a obra "Antropologia da criança" de Clarice Cohn, que propõe um novo ângulo de observação e metodologia para estudos ligados às crianças e aos adolescentes.

No que condiz à psicologia ambiental não houve aprofundamento teórico, mas apenas uma breve exposição de como a multidisciplinaridade torna-se necessária para compreensão do direito socioambiental e da própria complexidade da pessoa humana, pois são em ambientes cotidianos que o ser cresce, se desenvolve e revela processos de significação e identidade que são passíveis de estudo pela psicologia ambiental.

A fim de que fosse possível responder a indagação levantada, utilizou-se neste trabalho o método dedutivo, uma vez que se iniciou por uma visão ampla acerca do direito à moradia adequada até se chegar ao ponto essencial, restrito à análise do direito à moradia em interface com os direitos de personalidade e suas nuances no desenvolvimento infantojuveil.

Empregaram-se as técnicas de pesquisa indireta documental como, por exemplo, a Constituição Federal de 1988, o Estatuto da Criança e do Adolescente, o Pacto Internacional de Direitos Econômicos, Sociais e Culturais e o Comentário Geral $\mathrm{n}^{\mathrm{o}} 4$ sobre o Direito à Moradia Adequada, e a pesquisa indireta bibliográfica com a utilização de artigos científicos, teses e livros relacionados com o tema proposto.

\section{MAIS QUE UMA CASA: SOBRE O DIREITO À MORADIA ADEQUADA}

A moradia é recôndito humano de abrigo e proteção para o desenvolvimento físico, psicológico e social. Morar adquire significado amplo e no âmbito legal não é 
diferente. $\mathrm{O}$ termo moradia adequada busca resgatar a abrangência de tal direito a englobar vários elementos.

Referida expressão está contida no artigo 11 do Pacto Internacional de Direitos Econômicos, Sociais e Culturais de 1966, ao passo que, posteriormente, o Comentário Geral $\mathrm{n}^{0} .4$ sobre o Direito à Moradia Adequada, elaborado pelo Comitê de Direitos Econômicos, Sociais e Culturais, estabeleceu sete elementos que compõem a moradia adequada, também percebida como moradia digna.

Assim, a segurança jurídica da posse aparece como primeiro elemento do direito à moradia adequada. Em um raciocínio cadenciado na lógica de proteção aos componentes do direito à moradia adequada, vê-se que a princípio pretende-se a segurança da posse, ou seja, de estar naquele ambiente e ali permanecer, sem que haja a usurpação do direito de possuir com um mínimo de segurança de não ser retirado daquele local em virtude de arbitrariedades e da violência física.

Nas palavras de Nelson Saule Junior ${ }^{03}$ que aponta diferentes tipos de posse - como o aluguel, seja de caráter público ou privado, a moradia em cooperativa, o arrendamento ou a moradia do proprietário, bem como a moradia de emergência e os assentamentos informais - todas as formas de exercício do direito de morar devem ter "um grau de segurança de posse que lhes garanta a proteção legal contra despejo forçado, perturbação e qualquer tipo de outras ameaças".

No que tange à insegurança da posse, Raquel Rolnik ${ }^{04}$ expõe que

Fundamentalmente, a insegurança da posse é uma questão de economia política - leis, instituições e processos de tomada de decisão relacionados ao acesso e ao uso da moradia e da terra são atravessados pelas estruturas de poder existentes na sociedade. Assim, tanto as formas de gestão do solo como as estratégias de planejamento urbano têm uma enorme incidência sobre as possibilidades de acesso - ou bloqueio - à terra urbanizada para os moradores de menor renda. É no interior desta trama jurídico-administrativa que se tecem os mecanismos de inclusão/exclusão na cidade.

Mas na tentativa de ver protegido o espaço onde a moradia está construída e constituída, passa-se à estruturação do ambiente para a acolhida humana, o que indica a necessidade de infraestrutura básica de serviços como rede de esgoto,

\footnotetext{
${ }^{03}$ SAULE JUNIOR, Nelson. A proteção jurídica da moradia nos assentamentos irregulares. Porto Alegre: Sergio Antonio Fabris Editor, 2004, p.103

${ }^{04}$ ROLNIK, Raquel. Guerra dos lugares: a colonização da terra e da moradia na era das finanças. São Paulo: Boitempo, 2015, p. 151-152.
} 
acesso à água potável e rede elétrica, bem como coleta de lixo direta ou indireta, repercutindo a indissociabilidade do direito à moradia adequada com a efetivação do saneamento básico como "infraestrutura básica para a garantia da saúde, segurança, conforto e nutrição dos titulares do Direito" 05 .

Contudo, de acordo com a publicação "Direito à moradia adequada" ${ }^{\circ}$, por intermédio de dados obtidos junto ao Instituto Brasileiro de Geografia e Estatística (IBGE) por meio da síntese de indicadores sociais que analisam a condição de vida da população brasileira em 2010, somente $62,6 \%$ dos domicílios do Brasil possuíam abastecimento de água por rede geral, esgotamento sanitário e lixo coletado.

A Fundação João Pinheiro (FJP), no mesmo sentido, ao verificar o déficit habitacional 2013-2014 em solo brasileiro, aponta que a inadequação de moradias por carência de infraestrutura urbana alcançou, em 2014, 11, 275 milhões de domicílios não atendidos por ao menos um dos serviços, quais sejam, "iluminação elétrica, abastecimento de água com canalização interna, rede geral de esgotamento sanitário ou fossa séptica e coleta de lixo regular pelo menos duas vezes na semana" sem contabilizar as habitações precárias e os cômodos ${ }^{07}$.

Dessa maneira, nota-se que a realização do direito social fundamental à moradia demanda investimentos de ordem estrutural e, não apenas, sob uma limitação conjuntural, pois que as cidades precisam estar preparadas para oferecer serviços básicos de sobrevivência e dignidade para todos que nela habitam, independentemente do local onde esteja a moradia.

Em um terceiro viés o direito de morar não pode ser compreendido como mercadoria destinada ao patrimônio, vez que se concebido dessa maneira desvirtuará todo o entendimento relacionado ao direito à moradia. Nesse sentido, deve a moradia implicar gastos suportáveis que não restrinjam à manutenção plena de outros direitos também essenciais como alimentação e vestuário.

Resta incumbido aos Estados-partes, segundo entendimento de Saule Junior $^{08}$, o desenvolvimento de medidas que garantam o valor do aluguel ajustado à

${ }^{05}$ PANSIERI, Flávio. Eficácia e vinculação dos direitos sociais: reflexões a partir do direito à moradia. São Paulo: Saraiva, 2012, p. 27.

${ }^{06}$ BRASIL. Secretaria de Direitos Humanos da Presidência da República. Direito à moradia adequada. Brasília: Coordenação Geral de Educação em SDH/PR, Direitos Humanos, Secretaria Nacional de Promoção e Defesa dos Direitos Humanos, 2013. Disponível em: < http://www.sdh.gov.br/assuntos/bibliotecavirtual/promocao-edefesa/publicacoes-2013/pdfs/direito-a-moradia-adequada > . Acesso em: 30 abr. 2017, p. 47-48.

${ }^{07}$ FUNDAÇÃO JOÃO PINHEIRO. Centro de Estatísticas e Informações. Déficit habitacional no Brasil 2013-2104. Belo Horizonte, 2016. Disponível em < http://www.fjp.mg.gov.br/index.php/docman/cei/informativos-cei-eventuais/634-deficit-habitacional-06-09-2016/file > . Acesso em: 01 maio 2017, p. 80.

${ }^{08}$ SAULE JUNIOR, op. cit., p. 104. 
proporção da renda, a criação de subsídios para aqueles que não têm condições de morar adequadamente, o cumprimento do "princípio da possibilidade de custear a moradia", a fim de que inquilinos, por intermédio de instrumentos adequados, não sejam surpreendidos pelo aumento descomunal do aluguel e a garantia de materiais para construção habitacional.

Exsurge com isso interpretação ampla que não reduz a ideia de moradia enquanto casa que possui paredes e telhado. Ultrapassando tal concepção, a moradia passa a ser compreendida sob um viés constitucional que não se limita a uma abordagem voltada para o direito privado de cunho civilista, "Assim, o direito à moradia é caracterizado na atualidade tanto como direito de personalidade e como direito humano fundamental, posto que essencial para a proteção da própria existência física e, para além dela, uma existência com um mínimo de dignidade" ${ }^{09}$.

Como quarto elemento do direito à moradia adequada está a habitabilidade, possível de ser analisada sob diversos olhares complementares entre si, como, por exemplo, da arquitetura e da psicologia. A habitabilidade condiz com a condição física da casa de proporcionar ao indivíduo proteção contra chuvas, tempestades, como também em relação ao frio, ao calor, ao sol, entre outros acontecimentos naturais que não permitem a exposição contínua da pessoa.

Então que "A moradia adequada deve ser habitável, oferecendo aos seus habitantes o espaço adequado e protegendo-os do frio, da umidade, do calor, da chuva, do vento ou de outras ameaças à saúde, dos perigos estruturais e dos vetores de doença" ${ }^{10}$, logo se trata de componente diretamente relacionado com o direito à saúde, tendo em conta que a ausência de habitabilidade fragiliza a vitalidade corporal e enseja o desenvolvimento e a disseminação de doenças que poderiam ser evitas a partir da estruturação devida.

A acessibilidade, caracterizada como quinto elemento dentro do conceito de moradia adequada, está calcada no fato de que todos os grupos sociais, substancialmente minorias e grupos vulneráveis, também carecem de ter seu direito à moradia realizado e, como exemplo de tal constatação, tem-se as mulheres, as crianças e os adolescentes, os negros, as pessoas economicamente desfavorecidas, entre outras minorias.

Quanto à não discriminação e priorização de grupos vulneráveis, observemse as considerações veiculadas na cartilha "Como fazer valer o direito das mulheres à moradia?", especialmente no que condiz às mulheres.

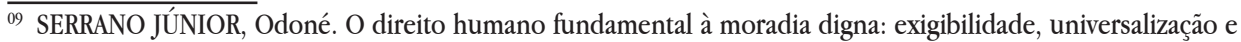
políticas públicas para o desenvolvimento. Curitiba: Juruá, 2012, p. 84.

${ }^{10}$ SAULE JUNIOR, op. cit., p. 104.
} 
No caso das mulheres, é importante que as políticas habitacionais levem em conta as necessidades dos diferentes grupos, especialmente os mais desfavorecidos, como as mulheres idosas, viúvas, mulheres com deficiência, com doenças crônicas, mães solteiras, chefes de família, lésbicas, transexuais, travestis, vítimas de violência doméstica, vítimas de desastres, imigrantes, deslocadas dentro de seu próprio país, entre outros ${ }^{11}$.

$\mathrm{Na}$ ampliação do ângulo de análise do direito à moradia adequada, o Comentário Geral $\mathrm{n}^{\mathrm{O}} 4$ ainda prevê a localização como quinto elemento. Considerando a ótica urbana e o diálogo permanente entre os direitos à terra, à moradia e à cidade, de nada adianta uma moradia em boas condições aquém da cidade, de forma que não permita acesso ao transporte, a hospitais e postos de saúde, escolas, creches, outros serviços públicos imprescindíveis, bem como opções de emprego ${ }^{12}$. Uma moradia excluída no contexto socioespacial é uma moradia marginalizada.

Ainda como último elemento tem-se a adequação cultural como pressuposto de inclusão e ao mesmo tempo como incentivo à manutenção da cultura local e regional quanto à construção das casas. Cabe ao Poder Público incentivar tal prática de modo que o aspecto cultural arquitetônico seja preservado ao longo do tempo como expressão da identidade e da diversidade cultural assegurada através da moradia $^{13}$.

Vistos os sete elementos que compõem o direito à moradia adequada notase que não se trata de um direito vazio, no sentido de não conter fundamentação suficiente, mas que propõe uma interpretação sobre o direito à moradia sob um prisma humanista que está direcionado em alcançar a dignidade da pessoa humana nas suas mais distintas variações durante a vida.

Morar é uma necessidade humana que existe desde o nascer até o morrer. A criança, o adolescente, o adulto e o idoso precisam de moradia para sobreviver que possibilite um desenvolvimento completo e uma vivência saudável. O direito à vida, à saúde, à intimidade são exemplos de como o direito à moradia adequada está atrelado aos direitos de personalidade que, por sua vez, podem ser estudados dentro de uma maior especificidade em relação aos direitos fundamentais infantojuvenis e seu desenvolvimento em meio ao ambiente de morada.

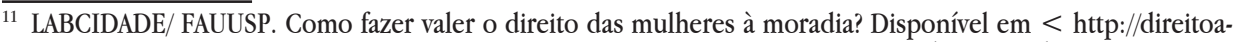
moradia.org/wp-content/uploads/2012/01/guia-mulheres-PT.pdf > . Acesso em: 04 abr. 2016, p. 20.

${ }^{12}$ SAULE JUNIOR, op. cit., p. 105.

${ }^{13}$ Ibid., p. 105.
} 
A título de exemplificação, Luiz Kohara, ao realizar pesquisa entre os anos de 2007 e 2009 sobre condições habitacionais e sua relação com o desempenho escolar de crianças, alunas da quarta série da Escola Municipal de Ensino Fundamental (EMEF) Duque de Caxias, com localização no bairro do Glicério, na cidade de São Paulo, área com concentração de cortiços, descobriu que índices de reprovação ligam-se diretamente às condições de moradia.

A pesquisa revelou condições precárias comuns nos domicílios localizados nos cortiços: falta de espaço para brincadeiras infantis; uso coletivo dos banheiros; grande concentração de pessoas; utilização de único cômodo de pequenas dimensões como moradia; falta de mobiliário; falta de janelas. Esses fatores, somados à rotatividade habitacional usual entre seus moradores, indicaram prejuízos sociais incalculáveis para as crianças, destacadamente o desenvolvimento escolar, sem falar de outras dimensões psicossociais. Conforme a somatória de situações precárias, menores são as chances de as crianças terem um bom desempenho escolar. As primeiras repercussões na vida escolar de tais crianças são cansaço excessivo nas aulas, grande quantidade de faltas, perda de materiais escolares e não realização das tarefas de casa. Essas dificuldades vão se acentuando, progressivamente, e o aprendizado torna-se penoso, levando-as à evasão escolar ${ }^{14}$.

A observação dos resultados obtidos pela pesquisa empreendida demonstra que a moradia tende a influenciar no rendimento escolar, visto que se trata de ambiente, assim como a escola, onde a criança e o adolescente passarão grande parte de suas vidas, por isso a necessidade também dimensionada sob tal aspecto, de que o direito à moradia seja protegido.

Nesse sentido, Sarlet ${ }^{15}$ aduz que a moradia encaixa-se nos ditos "direitos de subsistência, como expressão mínima do próprio direito à vida e, nesta perspectiva (bem como em função de sua vinculação com a dignidade da pessoa humana), é sustentada a sua inclusão no rol dos direitos de personalidade".

Contudo, antes desta abordagem é preciso compreender o Estatuto da Criança e do Adolescente (ECA) a partir da concepção de infância construída pela sociedade brasileira sob um horizonte antropológico.

\footnotetext{
${ }^{14}$ KOHARA, Luiz. A exploração nos cortiços do Centro e a luta pelo direito de morar dignamente. In: KOWARICK, Lúcio; FRÚGOLI JR, Heitor (Org.). Pluralidade urbana em São Paulo: vulnerabilidade, marginalidade, ativismos. São Paulo: Editora 34, FAPESP, 2016, p. 145.

${ }^{15}$ SARLET, Ingo Wolfgang. Algumas notas sobre a eficácia e efetividade do direito à moradia como direito de defesa aos vinte anos da Constituição Federal 1988. In: Direito à moradia adequada: o que é, para quem serve, como defender e efetivar. Belo Horizonte: Fórum, 2014, p. 268.
} 


\section{SER CRIANÇA E ADOLESCENTE}

O ordenamento jurídico brasileiro destina preocupação especial aos infantes e juvenis através de legislação datada de 13 de julho de 1990, intitulada Estatuto da Criança e do Adolescente (ECA), de acordo com a qual, crianças são aquelas que têm de 0 a 12 anos incompletos e adolescentes de 12 a 18 anos, conforme a norma contida no artigo $2^{\circ}$.

Com o advento da Constituição Federal de 1988, houve o rompimento do estigma vinculado à doutrina da Situação Irregular para se alcançar a inauguração da doutrina da Proteção Integral. A partir de tal ótica a norma inserta no artigo 226 da Constituição Federal determina que seja dever do Estado, da família e da sociedade a proteção das crianças e adolescentes, diante de todas as esferas de suas vidas.

Em via próxima encontra-se, também, o artigo $4^{\circ}$ do ECA ao fixar norma acerca dos direitos fundamentais infantojuvenis que, apesar de serem os mesmos destinados a qualquer pessoa, devem receber prioridade por parte do Estado e da comunidade como um todo. O conteúdo do referido artigo estabelece que

É dever da família, da comunidade, da sociedade em geral e do poder público assegurar, com absoluta prioridade, a efetivação dos direitos referentes à vida, à saúde, à alimentação, à educação, ao esporte, ao lazer, à profissionalização, à cultura, à dignidade, ao respeito, à liberdade e à convivência familiar e comunitária ${ }^{16}$.

O direito à vida e à saúde de crianças e adolescentes, até mesmo o direito à educação relacionam-se com o direito à moradia que, se adequada tende a contribuir para a efetivação dos direitos mencionados, pois que a moradia protege a integridade física e previne o surgimento de doenças decorrentes de estruturação precária e habitabilidade insuficiente ou inexistente.

Quanto à educação, nota-se pelo elemento da localização, componente do direito à moradia, que a "distância entre o lugar de moradia e a escola tem se mostrado particularmente relevante para a discussão do efeito do território no processo de escolarização das crianças de classes populares"17, ou seja, uma moradia excluída da proximidade com instituições básicas ou delas alienada pela impossibilidade de

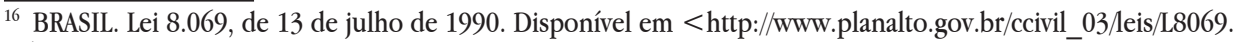
$\mathrm{htm}>$. Acesso em 13 jan. 2017.

${ }^{17}$ SALATA, André Ricado; SANT'ANNA, Maria Josefina Gabriel. Entre o mercado de trabalho e a escola: os jovens no Rio de Janeiro. In: RIBEIRO, Luiz Cesar de Queiroz [et al.]. Desigualdades urbanas, desigualdades escolares. Rio de Janeiro: Letra Capital: Observatório das Metrópoles: IPPUR/UFRJ, 2010, p. 21.
} 
acesso, como a escola, dificulta a concretização do direito à educação.

Todavia, este trabalho não tem o pretexto de analisar tais questões em profundidade teórica, mas tão somente demonstrar que estão interligadas, de maneira que a inefetividade de um direito repercute nos demais, quase como um trilho de dominó ao levar o primeiro toque e esbarrar nos seguintes.

A intenção do presente capítulo é entender por qual razão, do ponto de vista antropológico em comunicação com a ciência jurídica, criou-se no Brasil o ECA. Investiga-se por meio da interdisciplinaridade com a antropologia, o embasamento sob o qual o Estatuto está edificado, qual o seu valor fundamente,

não podemos esquecer que freqüentemente um diálogo com as ciências jurídicas pode ser frutífero ao estudo antropológico. [...] só podemos entender o Estatuto da Criança e do Adolescente vigente hoje no Brasil, assim como as polêmicas que o rodeiam, se compreendermos a concepção de criança e infância que o embasa. Por outro lado, as legislações afetam, em maior ou menor grau, as crianças, e uma boa compreensão desse contexto jurídico - como do institucional que lhe é correlato, seja escolar, de assistência ou punitivo - pode ser revelador na pesquisa que tem como foco as crianças ${ }^{18}$.

Importa dizer que o cuidado especial destinado às crianças e aos adolescentes não é algo disperso na legislação brasileira, mas está conectado com a forma pela qual a sociedade brasileira percebe a criança e a infância.

Nesse viés, juntamente com a lei que é alterada no tempo, a antropóloga Clarice $\mathrm{Cohn}^{19}$, a discorrer sobre uma nova antropologia da criança, afirma que a começar pela década de 60 os antropólogos passaram a reavaliar suas concepções, de forma que conceitos centrais recebessem outras roupagens, o que permitiu estudos renovadores acerca da criança.

Rever a sociedade implica rever também o papel do indivíduo dentro dela. Se a sociedade é constantemente produzida, ela não poderá sê-lo se não pelos indivíduos que a constituem. Portanto, ao invés de receptáculos de papéis e funções, os indivíduos passam a ser vistos como atores sociais. Se antes eram atores no sentido de atuar em um papel, agora eles o são no sentido de atuar na sociedade recriando-a a todo momento ${ }^{20}$.

\footnotetext{
${ }^{18}$ COHN, Clarice. Antropologia da criança. Rio de Janeiro: Zahar, 2005, p. 44.

${ }^{19}$ Ibid., p. 18-19.

${ }^{20}$ Ibid, p. 20.
} 
Da mesma forma que as leis mudam com a sociedade, é preciso observar os indivíduos enquanto atores sociais que exercem influências nas modificações sociais e passam a ser vistos como atores sociais. Com a Constituição de 1988 e o ECA, pode-se dizer que crianças e adolescentes passaram a ser percebidos como sujeitos em condição peculiar de desenvolvimento, considerados reais atores sociais.

No entendimento de Cohn, "a infância é um modo particular, e não universal, de pensar a criança." ${ }^{21}$ associado com a ideia de que a infância é uma construção social e histórica do Ocidente, em que os direitos infantojuvenis e a concepção de menoridade ligam-se ao que a autora denomina de "formação de um sentimento e de uma concepção de infância”22.

A partir de então, a criança e o adolescente, na conjuntura do ECA, não são mais notados como engrenagens generalizadas do meio social assim como qualquer outro indivíduo. Eles progridem de objeto de direitos para sujeitos de direitos com prerrogativas e deveres próprios, pertinentes à peculiaridade que lhes é intrínseca, não persistindo a ideia de que sejam "futuros adultos", mas crianças e adolescentes.

A criança atuante é aquela que tem um papel ativo na constituição das relações sociais em que se engaja, não sendo, portanto, passiva na incorporação de papéis e comportamentos sociais. Reconhecê-lo é assumir que ela não é um "adulto em miniatura", ou alguém que treina para a vida ativamente com os adultos e as outras crianças, com o mundo, sendo parte importante na consolidação dos papéis que assume e de suas relações ${ }^{23}$.

Interpreta-se que por intermédio do ECA houve o reconhecimento, tanto da criança quanto do adolescente, como atuantes com papéis ativos na constituição das relações sociais, da forma como coloca Cohn.

$\mathrm{Na}$ época da elaboração do ECA, a percepção de sujeitos de direitos já se tornou real, pois que o Estatuto contempla na norma contida no artigo 16, IV, o direito de brincar, sendo este oriundo da vontade das crianças ao serem perguntadas sobre o que queriam que constasse na lei que falaria de seus direitos ${ }^{24}$.

Nessa ótica, o Estatuto da Criança e do Adolescente, ao romper com o estigma de infantes e juvenis "inferiores" em conhecimento e taxadamente tidos como "menores" de alguma forma dentro do seio da sociedade, os entende como

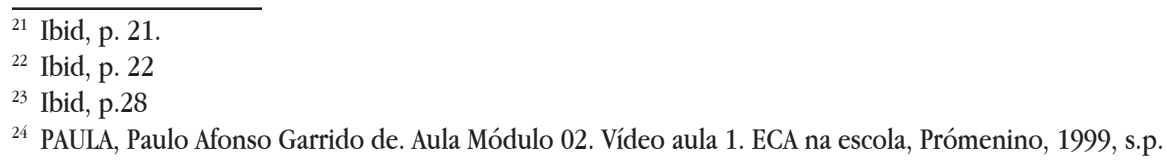


personagens principais de suas histórias que, aliados à natural ludicidade do ser, desejaram incluir o brincar como um dos aspectos do direito de liberdade.

Destarte, percebe-se que a forma pela qual a criança absorve as vivências do mundo é distinta do adulto, o que não significa que ela seja "menor" que o adulto em intelectualidade, mas que determina o significado das coisas de modo diverso, com saber diferenciado.

Quando a cultura passa a ser entendida como um sistema simbólico, a idéia de que as crianças vão incorporando-a gradativamente ao aprender "coisas" pode ser revista. A questão deixa de ser apenas como e quando a cultura é transmitida em seus artefatos (sejam eles objetos, relatos ou crenças), mas como a criança formula um sentido ao mundo que a rodeia. Portanto, a diferença entre as crianças e os adultos não é quantitativa, mas qualitativa; a criança não sabe menos, sabe outra coisa ${ }^{25}$.

Continuamente, referida autora complementa que "A formulação da criança é completa" ${ }^{26}$, mas que por não ser idêntica ao pensar adulto tende a criar uma "incapacidade de se comunicar com as crianças, de vê-las como sujeitos sociais" ${ }^{27}$.

Como este artigo propõe uma análise dos direitos de personalidade em meio ao direito à moradia adequada em função do desenvolvimento infantojuvenil, buscou-se por meio de uma antropologia da criança, entender a motivação da sociedade brasileira ao erigir o ECA como principal legislação em prol dos direitos de crianças e adolescentes.

Dessa maneira, o ECA, decorrido da Constituição Federal de 1988, não diferentemente do que acontece em outros países, é fruto de uma construção social e histórica, pois "não há imagem produzida sobre a criança e a infância, ou pela criança, que não seja, de algum modo, produto de um contexto sociocultural e histórico específico" 28 .

Em que pese o ECA tenha 26 anos de história e vigência no Brasil, as crianças e os adolescentes vivenciam diariamente violências e situações degradantes que não correspondem à proteção corroborada no artigo $4^{\circ}$ do Estatuto. No que diz respeito aos seus direitos de personalidade em consonância com a efetividade do direito fundamental social à moradia não é diferente.

\footnotetext{
${ }^{25}$ COHN, op. cit., p. 33, grifo nosso.

${ }^{26}$ Ibid., p. 34-35.

${ }^{27}$ Ibid, p. 45.

28 Ibid., p. 50.
} 
Adiante, serão analisados alguns direitos de personalidade em interface com o direito à moradia adequada, já conceituada anteriormente, de modo que seja possível compreender a importância da proteção de mencionado direito no contexto infantojuvenil. Isto porque o espaço interfere no desenvolvimento humano desde o nascimento até a morte e, as crianças e adolescentes, para que tenham seus direitos respeitados, carecem de um ambiente adequado para viverem.

\section{DIREITOS DE PERSONALIDADE EM RELAÇÃO AO DIREITO À MORADIA: A OBSERVAÇÃO DE REFLEXOS NO DESENVOLVIMENTO INFANTOJUVENIL}

Como visto anteriormente, a moradia digna é composta por sete elementos que a validam como adequada a partir de necessidades básicas do ser humano. Para Souza ${ }^{29}$, a moradia é considerada direito interdependente aos demais direitos alusivos à personalidade humana em virtude de um eixo particular que está centrado na pessoa, logo, natural a intersecção de direitos que cuidam da proteção de um objetivo comum.

$\mathrm{Na}$ concepção de Carlos Alberto Bittar, mais do que a proteção de um objetivo comum, os direitos da personalidade têm relevância social e importância para a formação humana, assim "é imprescindível tornar possível o acesso aos direitos da personalidade, para além de sua positivação no direito, por meio de sua plenificação na vida dos cidadãos, normalmente alijados de sua proteção"30.

Observa-se, ainda, que os direitos de personalidade presentes no Código Civil pátrio têm previsão literal no artigo $5^{\circ}$ da Constituição Federal ou, mesmo que implicitamente referenciados, estão conectados à dignidade humana que possui proteção expressa no artigo $1^{\circ}$ da Constituição, o que faz Anderson Schreiber entender que "Os direitos da personalidade são, portanto, direitos fundamentais", contudo adverte que não são todos os direitos fundamentais que podem ser vistos como direitos de personalidade, como, por exemplo, o direito de herança e o direito de propriedade ${ }^{31}$.

Dessa forma, associa-se ao pensamento de Schreiber a explicação de Bittar ao afirmar que não é mais possível a manutenção de "construções dogmáticas mais

\footnotetext{
${ }^{29}$ SOUZA, Sérgio Iglesias Nunes de. Direito à moradia e de habitação: análise comparativa e suas implicações teóricas e práticas com os direitos da personalidade. 2. ed. São Paulo: Revista dos Tribunais, 2008, p. 191.

${ }^{30}$ BITTAR, Carlos Alberto. Os direitos da personalidade. 8. ed. São Paulo: Saraiva, 2015, p. 32.

${ }^{31}$ SCHREIBER, Anderson. Direitos da personalidade. 2. ed. São Paulo: Atlas, 2013, p. 14.
} 
tradicionais", o que alimenta a tendência progressiva de assimilação mais intensa de que "os direitos humanos se traduzam em exigências de direitos fundamentais, e que os direitos fundamentais se traduzam em direitos da personalidade, integralizandose no ordenamento jurídico"32.

Verifica-se, então, a pertinência da análise do direito fundamental social à moradia adequada com relação aos principais direitos de personalidade, sendo possível tecer apontamentos de suas interfaces em sintonia especial com o desenvolvimento infantojuvenil, tendo em conta que a essencialidade de mencionado direito liga-se à ideia de um ambiente propício para o desenrolar da vida aliada à adequação física do espaço em condições dignas de sobrevivência.

Inicia-se pelo direito à vida, elementar à existência de todos e firmada em aspectos físicos ou biológicos ${ }^{33}$, com manifestação desde a concepção, mas condicionado ao nascimento do ser com vida, é o direito mediante o qual os demais direitos gravitam, tendo adquirido a noção de "dignidade na qualificação da vida", com viés não apenas individualista ${ }^{34}$.

No que concerne ao direito à vida em contato direto com o direito à moradia, situam-se indagações como, por exemplo, se o direito à moradia existe ao passo em que há o nascimento com vida da pessoa humana ou se persiste a necessidade de ser feito algum contrato ou ato para sua existência.

Diante de tais questionamentos, entende-se, de acordo com Souza ${ }^{35}$, que a existência do direito à moradia independe de contrato ou mesmo "da criação do direito em decorrência da lei", diferentemente do que acontece com o direito real de habitação, instituto de origem civil que não se confunde com a moradia, direito fundamental social possuidor de natureza constitucional.

Complementa-se que "o direito à moradia surge com o nascimento da pessoa humana, sob a condição de o nascimento ser com vida, permanecendo integrado à pessoa até a sua morte." ${ }^{36}$, no mesmo sentido do entendimento já apresentado de Carlos Alberto Bittar. Todavia, a extensão da análise objeto da pesquisa do autor Sérgio Iglesias Nunes de Souza, ao passo que orienta o desenvolvimento deste capítulo, propõe que se pense acerca do recém-nascido, da criança e do adolescente na perspectiva do direito à moradia.

\footnotetext{
32 BITTAR, op. cit., p. 61.

33 SANTOS, Alessandra Figueiredo dos; MARTINEZ, Sérgio Rodrigo. Os direitos da personalidade no código civil: o conceito de vida e suas implicações ambientais. Revista Argumenta, Jacarezinho, n. 11, p. 51-73, 2009 , p. 67.

${ }^{34}$ BITTAR, op. cit., p. 120-121.

35 SOUZA, op cit., p. 194.

36 Ibid, p. 194.
} 
Para Silvio Romero Beltrão, o fato de a pessoa humana ser sujeito de direitos da personalidade faz com que haja uma dinâmica de referidos direitos ao passo que "sofre níveis de evolução em face do objeto a ser tutelado, ou seja, do recém-nascido ao idoso, há peculiaridades de cada fase que merece ser respeitada enquanto "expressão de sua personalidade" 37 .

Assim, a condição econômica não pode balizar a efetivação dos direitos sociais, ainda mais quando se refere a um público ao qual é destinada atenção especial pela legislação brasileira como é o caso dos infantes e juvenis, que possuem um microssistema jurídico próprio para a sua proteção.

Com isso, Souza observa que a dificuldade ou incapacidade econômica dos genitores não é argumento válido para relevar a ausência de uma casa adequada com consequente proteção para o recém-nascido, considerando, de modo peculiar, a fragilidade de seu corpo e de sua saúde em meio ao ambiente que o cerca ${ }^{38}$. A partir disso, mencionado pesquisador desenvolveu a seguinte ideia:

A vedação ao pleno exercício do direito à moradia também constitui um atentado ao seu direito à vida. Sem o exercício do direito à moradia, fere-se, por derradeiro, o próprio direito à vida ou à integridade física, colocando à sorte a incolumidade física do próprio recém-nascido, da criança e também do adolescente ${ }^{39}$.

Como exemplo, "A falta de higiene, a precariedade de vida em casas com insuficiência estrutural de saneamento, demonstrando condições subumanas de moradia, refletem a lesão ao referido direito." ${ }^{40}$.

A importância do direito à moradia não encontra guarida literal no Estatuto da Criança e do Adolescente, no sentido de que não há expressão direta que afirme esse entendimento. Porém, por intermédio da interpretação dos artigos $7^{\circ}, 18$ e $19^{41}$, é possível identificar a necessidade implícita da moradia adequada e a importância desse direito, pois que está interrelacionado a outros.

$\mathrm{O}$ artigo $7^{\circ}$ exprime a seguinte ideia a partir da proteção de dois direitos vitais, a vida e a saúde: "A criança e o adolescente têm direito a proteção à vida e à saúde, mediante a efetivação de políticas sociais públicas que permitam o nascimento e o desenvolvimento sadio e harmonioso, em condições dignas de existência.”².

\footnotetext{
${ }^{37}$ BELTRÃO, Silvio Romero. Direitos da personalidade: de acordo com o Novo Código Civil. São Paulo: Atlas, 2005 , p. 81.

${ }^{38}$ SOUZA, op. cit., p. 194.

${ }^{39}$ Ibid., p. 194

${ }^{40}$ Ibid., p. 148.

${ }^{41}$ Ibid, p. 195.

${ }^{42}$ BRASIL, op. cit., s.p.
} 
Veja-se que quando o artigo coloca "condições dignas de existência", ele pressupõe a imprescindibilidade de um ambiente adequado para o desenvolvimento infantojuvenil, onde o indivíduo consiga viver de maneira sadia e harmoniosa, ao ponto de que haja a efetivação de políticas sociais públicas que atendam a população.

Nesta esteira, o artigo 18 dispõe que "É dever de todos velar pela dignidade da criança e do adolescente, pondo-os a salvo de qualquer tratamento desumano, violento, aterrorizante, vexatório ou constrangedor." ${ }^{3}$. Com isso acrescenta-se que um tratamento não desumano está preenchido de dignidade em todas as esferas nas quais a vida acontece, estendendo interpretação semelhante à moradia adequada, enquanto espaço que deve estar regado de humanidade.

Na sequência, o artigo 19 salienta que a criança e o adolescente têm o direito de "ser criado e educado no seio de sua família e, excepcionalmente, em família substituta, assegurada a convivência familiar e comunitária, em ambiente que garanta seu desenvolvimento integral."

A redação da transcrita norma contida no artigo 19 foi dada pela lei $\mathrm{n}^{\circ}$. 13.257/2016 que dispõe sobre políticas públicas para a primeira infância e altera o ECA, dentre outros diplomas legais. Observa-se que há o acréscimo da expressão "ambiente que garanta seu desenvolvimento integral", o que demonstra novamente interpretação voltada para o direito à moradia.

Diante da análise das três normas já apontadas, Souza concluiu que

Seriam tais direitos possíveis de serem exercidos, se não houvesse o direito à moradia como elemento base de proteção àquela criança ou adolescente? Não, porque o direito à moradia é basilar, assim como o direito à vida, posto que, sem aquele, outros direitos ficariam impossibilitados de serem exercidos à altura de condições dignas de existência - questão esta central sob o enfoque dos direitos da personalidade ${ }^{44}$.

Considerando que o direito à moradia é basilar, da mesma forma que o direito à vida, empreendeu-se breve pesquisa a fim de encontrar a expressão "moradia" no texto legal intitulado ECA, por meio do acesso à lei n ${ }^{\circ} .8 .069$ de 13 de julho de 1990, especificamente pela via online disponibilizada pelo site do Planalto, ao se escrever o termo moradia no localizador contido em referida página, a palavra em questão foi encontrada em dois momentos.

\footnotetext{
${ }_{43}$ Ibid, s.p.

${ }^{44}$ SOUZA, op. cit., p. 195.
} 
$\mathrm{O}$ primeiro deles é no parágrafo único do artigo $3^{\circ}$, incluído pela lei $\mathrm{n}^{\mathrm{o}}$. 13.257/2016. Dito parágrafo acrescenta que

Os direitos enunciados nesta Lei aplicam-se a todas as crianças e adolescentes, sem discriminação de nascimento, situação familiar, idade, sexo, raça, etnia ou cor, religião ou crença, deficiência, condição pessoal de desenvolvimento e aprendizagem, condição econômica, ambiente social, região e local de moradia ou outra condição que diferencie as pessoas, as famílias ou a comunidade em que vivem ${ }^{45}$.

Sob o prisma da igualdade na aplicação do ECA a todas as crianças e adolescentes independente de qualquer condição ou rótulo social, há descrição literal que apõe "local de moradia", a possibilitar um raciocínio direcionado para a não diferenciação ocasionada pela exclusão socioespacial que resulta em um estigma inerente ao território, transmudado para as pessoas que ali moram, inclusive infantes e juvenis.

O segundo momento em que a palavra moradia foi encontrada consta na norma do artigo 130 do ECA ao dizer que "Verificada a hipótese de maus-tratos, opressão ou abuso sexual impostos pelos pais ou responsável, a autoridade judiciária poderá determinar, como medida cautelar, o afastamento do agressor da moradia comum" 46 .

Trata-se, de modo não especificado, de proteger a criança e/ou adolescente vítima no local onde deveria existir um resguardo natural para segurança daqueles que carecem de outros indivíduos para orientarem seu desenvolvimento. Referido local é a moradia, espaço íntimo de vivência, de acordo com o qual é preciso prevalecer não só condições dignas de sobrevivência, mas também ambiente de acolhida entre todos os moradores.

A moradia mostra-se necessária em diversas faces da vida e em virtude disso influencia a construção da personalidade humana, pois é na moradia condigna que a vida acontece.

O ECA, nesse sentido, tenta proteger o espaço onde a criança está habituada e passa a criar sua identidade, mediante a incorporação de aspectos vividos e memórias formadas, até mesmo para preservação da criança e do adolescente em meio à comunidade e às pessoas que lhes são conhecidas e acabam por fazer parte da sua história, como amigos em proximidade territorial, vizinhos, e também locais de

\footnotetext{
45 BRASIL, op. cit., s.p, grifo nosso.

46 Ibid., s.p., grifo nosso.
} 
lazer e divertimento, sejam parques, prédios comunitários com eventos tradicionais, escola, creche, entre outros ambientes.

A partir dessa interpretação é possível tentar estabelecer mais um diálogo multidisciplinar. No capítulo anterior viu-se o liame entre a visão antropológica da criança com o estudo do direito infantojuvenil, de maneira que fosse viável a compreensão do ECA e a razão que o fez ser criado, ou seja, a verificação da concepção de criança e infância para o consequente entendimento legal.

Neste átimo segue-se com raciocínio semelhante, mas com interfaces para a psicologia ambiental. Não se pretende esmiuçar o conceito de tal área da ciência e tampouco desenvolvê-la integralmente quanto ao tema aqui proposto, mas buscase demonstrar que há estudos voltados para a intersecção entre ser humano e ambiente, pois que ambos coexistem em mútua interferência.

Esta psicologia tem como objeto de estudo a relação e as inter-relações entre pessoa e ambiente e os processos afetivos e cognitivos humanos envolvidos neste ambiente social, histórico, cultural e físico. Desta forma, a psicologia ambiental volta-se para a forma que as pessoas sentem, pensam e vivenciam o espaço em que estão implicadas. Pautando-se não somente na compreensão dos problemas ambientais, mas, sobretudo, na questão da sustentabilidade da vida enquanto responsabilidade dos seres humanos e na preocupação com a humanidade. ${ }^{47}$

Com isso, as autoras Deyseane Maria Araújo Lima e Zulmira Áurea Cruz Bomfim $^{48}$, ao mencionarem os ensinamentos de Gabriel Moser, dão um exemplo de significação do espaço através da residência.

De acordo com Moser (2001), a subjetividade está relacionada aos espaços cotidianos, pois estes promovem processos de significação e de identificação das pessoas com estes, como por exemplo, a residência pode ser considerada um lugar, um espaço de referência básica para a construção de um sentido de proteção e de segurança.

Pela compreensão de residência, no panorama até então construído, pode-se remetê-la à moradia enquanto direito social que antecede outros direitos fundamentais. Veja-se que em espaços cotidianos são criados processos de

\footnotetext{
$\overline{47}$ LIMA, Deyseane Maria Araújo; BOMFIM, Zulmira Áurea Cruz. Vinculação afetiva pessoa-ambiente: diálogos na psicologia comunitária e psicologia ambiental. Psico, Porto Alegre, PUCRS, v. 40, n. 4, pp. 491-497, out./dez. 2009 , p. 492.

${ }^{48}$ Ibid., p. 495.
} 
significação e identificação entre pessoas e ambientes, ao passo que a residência pode ser referência na elaboração de uma ideia de proteção e segurança.

Pode-se, então, veicular uma associação entre a moradia e a intimidade, direito inerente à pessoa, ao passo que "O ser do homem é um ser espacial, sua intimidade tem a necessidade de uma morada" ${ }^{49}$. Entenda-se "ser do homem" como ser humano, de modo amplo e igualitário, entre todas as pessoas.

A intimidade para ser desenvolvida seja por uma criança ou por um idoso, carece de um espaço apropriado que é facilmente reconhecido na moradia. Nas considerações de Marcos César Botelho, a intimidade pode ser pensada como um "santuário do humano", a qual apenas o ser que ali habita pode acessar, tida como essencial para o indivíduo, pois que viabiliza sentimentos naturais de proteção como a vergonha ou o pudor ${ }^{50}$.

Para se ter uma ideia do alcance do direito à intimidade, Bittar descreve elementos que compóem a esfera íntima da pessoa, quais sejam, "a vida privada; o lar; a família; a correspondência" ${ }^{1}$. Nota-se que a dimensão do lar é protegida pela moradia, bem como a vida privada, a família e a correspondência.

Além dos direitos de personalidade já comentados, como a vida, a saúde, a segurança e a intimidade, a moradia relaciona-se com outros deles, conforme abordados por Souza (2008) e que são sintetizados por Sarlet ${ }^{52}$ ao descrever sobre um espaço essencial para viver.

Com efeito, sem um lugar adequado para proteger-se a si próprio e a sua família contra as intempéries, sem um local para gozar de sua intimidade e privacidade, enfim, de um espaço essencial para viver com um mínimo de saúde e bem estar, certamente a pessoa não terá assegurada a sua dignidade, aliás, por vezes não terá sequer assegurado o direito à própria existência física, e, portanto, o seu direito à vida.

Com isso, pode-se falar ainda no direito à integridade pessoal que engloba a integridade física, psíquica ou moral, "de forma que toda pessoa tem direito a que

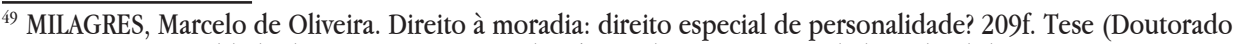
em Direito) Faculdade de Direito, Programa de Pós-Graduação, Universidade Federal de Minas Gerais, 2009, p. 123.

50 BOTELHO, Marcos César. A equiprimordialidade entre autonomia pública e privada como forma de garantia da intimidade e da privacidade. Revista Argumenta, Jacarezinho, n. 12, p. 287-305, 2010, p. 290.

${ }^{51}$ BITTAR, op. cit., p. 173.

52 SARLET, Indo Wolfgang. O direito fundamental a moradia na Constituição: algumas anotações a respeito de seu contexto, conteúdo e possível eficácia. Revista Brasileira de Direito Público - RBDP, Belo Horizonte, ano 1, n. 02, p. 65-119, jul./set.2003, p. 15.
} 
se respeite sua integridade física e moral para o exercício do direito adequado de moradia" ${ }^{\prime 3}$.

$\mathrm{O}$ direito à integridade física refere-se "ao modo de ser físico da pessoa, partindo da noção de direito à vida, onde se constrói a idéia única da existência, sendo a integridade física parte desta idéia, concentrada na manutenção dos atributos e características físicas da pessoa" ${ }^{44}$.

Porém, a integridade física e psíquica de crianças e adolescentes não tem sido amplamente respeitada, conforme aponta notícia online publicada em 10 de abril de 2015 e atualizada em 15 de abril de 2015, intitulada "Abandonadas e descartadas: mais de 150 milhões de crianças vivem nas ruas, alertam especialistas da ONU", publicada pela ONUBR (Nações Unidas no Brasil) ${ }^{55}$.

Em subtítulo contido na mesma matéria, consta que "Relatoras especiais em direitos humanos da ONU cobram mais investimentos dos Estados para garantir direitos básicos das crianças, como moradia e educação", de modo que mais de 150 milhões de crianças em todo o mundo estão sem moradias, como população em situação de rua.

Isso as coloca em situação de maior vulnerabilidade e implica, segundo Maud Boer-Buquicchio, relatora especial da ONU (Organização das Nações Unidas) para venda e exploração sexual de crianças, "um alto risco de serem sexualmente exploradas", sendo que muitas vezes

estão escapando da pobreza, de moradias inadequadas, famílias desestruturadas, violência doméstica, desalojamento, desastres naturais, conflitos e guerras. Elas tomam as ruas porque não há outro lugar para onde ir. Uma vez nas ruas, elas sofrem discriminação e estigmatização ${ }^{56}$.

Nesta notícia, a relatora especial da ONU para o direito à moradia adequada, Leilani Farha, expõe acerca da interferência da crise econômica no acesso qualitativo e quantitativo a recursos em esfera local e nacional.

Entretanto, a moradia, enquanto direito conexo aos direitos da personalidade não pode ser objetificada como mercadoria, pois que ao mesmo tempo em que

\footnotetext{
53 SOUZA, op. cit., p. $154-155$.

${ }^{54}$ BELTRÃO, op. cit., p.108.

55 BRASIL. ONUBR. Abandonadas e descartadas: mais de 150 milhões de crianças vivem nas ruas', alertam especialistas da ONU. Disponível em < https://nacoesunidas.org/abandonadas-e-descartadas-mais-de-150-milhoesde-criancas-vivem-nas-ruas-alertam-especialistas-da-onu/ > . Acesso em 13 dez. 2015, s.p.

${ }^{56}$ Ibid, s.p.
} 
a moradia existe ou é adequada pelo poder de consumo associado à capacidade econômico-financeira de tê-la, o ser humano torna-se igualmente um objeto, como produto apreciado ou não, conforme seu "valor" para consumir e ser consumido, verdadeira mercadoria ${ }^{57}$.

Se a moradia enquanto direito fundamental social, necessária para que todas as pessoas vivam com dignidade no exercício de direitos da personalidade, é limitada em sua concretização por crises econômicas, há que se dizer que o direito de liberdade também é afetado.

Trata-se de direito estudado por Souza em dependência ao direito à moradia que aufere uma gama de entendimentos ${ }^{58}$, mas que neste trabalho apresenta duas concepções: liberdade de exercer o direito à moradia adequada e liberdade a partir do direito à moradia adequada.

A liberdade para exercer o direito à moradia adequada nasce com o ser humano, pois todas as pessoas são possuidoras do direito de morar adequadamente ainda quando recém-nascidas. Com isso, é preciso existir liberdade na ocupação do espaço, seja pela propriedade, pelo pagamento de aluguel para ali estar, pela formação de assentamentos irregulares que buscam regularização fundiária, seja pelo direito de laje, ou outras formas, ainda que, a princípio, sejam ditas ilegítimas pelo direito.

Em conexão a tal ponto e diante das proposições já expostas, pode-se pensar que o preço monetário do espaço tende a ditar o exercício da liberdade a partir do direito à moradia adequada. Moradias precárias e indivíduos que sequer têm contato com ambientes dignos de sobrevivência podem ter sua capacidade de participação social afetada, assim como seu núcleo essencial enquanto pessoa.

Direitos sociais são premissas fundamentais para a construção da democracia $^{59}$. A liberdade de escolha e discernimento tem ampla relação com a condição de vida dos sujeitos que necessitam de requisitos mínimos de existência digna, preenchidos para o desenvolvimento pessoal, profissional e até mesmo psicológico.

Assim, a efetividade do direito à moradia, como cuidado para os direitos de personalidade de crianças e adolescentes que estão em condição peculiar de

\footnotetext{
${ }^{57}$ BAUMAN, Zigmunt. Vidas para consumo: a transformação das pessoas em mercadorias. Tradução de Carlos Alberto Medeiros. Rio de Janeiro: Jorge Zahar, 2008, p. 18.

${ }^{58}$ SOUZA, op. cit., p. 224.

${ }^{59}$ ALVES, Fernando de Brito. Constituição e participação popular: a construção histórico-discursiva do conteúdo jurídico-político da democracia como direito fundamental. Curitiba: Juruá, 2013, p. 254.
} 
desenvolvimento, significa um investimento humano e ao mesmo tempo de resultados que implicarão modificações organizacionais na sociedade, em especial no que tange à democracia, conforme entende Fernando de Brito Alves.

Necessário ressaltar que, ainda sob o aspecto material, os direitos sociais se constituam como pressuposto básico da democracia, assumindo assim um aspecto compensatório, de modo que modificações no seu conjunto continuam sendo relevantes tanto nos países centrais quanto nos países de modernidade tardia, e estruturam relações sempre novas entre Estado-Sociedade e Estado-mercado, tendo produzido impactos relevantes sobre a questão da democracia ${ }^{60}$.

Além de a moradia possibilitar que o ser seja encontrado no espaço ${ }^{61}$, ela está interconectada a vários direitos fundamentais que ancoram vieses de dignidade. A proteção de tal direito contempla direitos de personalidade e reforça destaque, especialmente, quanto aos direitos infantojuvenis.

\section{CONSIDERAÇÕES FINAIS}

A violação de um ou de vários elementos do direito à moradia é suficiente para afetar direito(s) de personalidade, como, por exemplo, na ausência de saneamento básico adequado em relação à prejudicialidade do direito à saúde, bem como do direito à vida e da integridade pessoal.

Entende-se que os direitos de personalidade são transversais ao direito à moradia e, por isso, uma violação mínima ao direito de morar tem repercussão nos direitos de personalidade de todos os indivíduos que vivem naquele espaço, especialmente no que tange às crianças e aos adolescentes enquanto pessoas em condição peculiar de desenvolvimento.

O ordenamento jurídico brasileiro dispensa atenção específica para infantes e juvenis por intermédio do ECA que, por sua vez, reúne uma série de direitos e deveres direcionados para o público infantojuvenil, a fim de que tenham prioridade e sejam cuidados pelo Estado, pela família e pela sociedade.

Considerando a peculiar preocupação com crianças e adolescentes, verificou-se que o ECA traduz a necessidade de proteção do direito à moradia pela

\footnotetext{
${ }^{60}$ Ibid, p. 254.

${ }^{61}$ MILAGRES, op. cit., p. 119.
} 
descrição dos direitos das crianças e dos adolescentes, não persistindo literalidade que aponte para o reconhecimento explícito de tal direito. O termo "moradia" é utilizado duas vezes no Estatuto e possui representações contextuais diferentes.

Nesse sentido, um olhar antropológico direcionado para a concepção de infância permite entender a criação do ECA, ao tratar do reconhecimento da criança enquanto sujeito social que reúne formas de absorção do mundo de modo diverso dos adultos. O Estatuto ao ser elaborado e propagado reconhece infantes e juvenis como sujeitos de direitos.

Entretanto, existem violações contínuas contra crianças e adolescentes como é o caso, por exemplo, das pessoas em situação de rua, que não possuem o direito à moradia efetivado e, seguidamente, têm os direitos de personalidade afetados em uma cadência lógica que fere a vida digna e a dignidade humana com implicações no desenvolvimento infantojuvenil quanto ao direito à vida, à saúde, à integridade pessoal e à liberdade.

Para a concretização dos objetivos erigidos pela Constituição Federal de 1988, porém, essencial se faz que os direitos de personalidade sejam amplamente respeitados, a fim de que a pessoa desenvolva suas potencialidades, autonomia e empoderamento para a consecução do ideal democrático que prescinde da efetivação dos direitos sociais, entre eles, o direito à moradia adequada.

\section{REFERÊNCIAS}

ALVES, Fernando de Brito. Constituição e participação popular: a construção histórico-discursiva do conteúdo jurídico-político da democracia como direito fundamental. Curitiba: Juruá, 2013.

BAUMAN, Zigmunt. Vidas para consumo: a transformação das pessoas em mercadorias. Tradução de Carlos Alberto Medeiros. Rio de Janeiro: Jorge Zahar, 2008.

BELTRÃO, Silvio Romero. Direitos da personalidade: de acordo com o Novo Código Civil. São Paulo: Atlas, 2005.

BITTAR, Carlos Alberto. Os direitos da personalidade. 8. ed. São Paulo: Saraiva, 2015. 
BOTELHO, Marcos César. A equiprimordialidade entre autonomia pública e privada como forma de garantia da intimidade e da privacidade. Revista Argumenta, Jacarezinho, n. 12, p. 287-305, 2010.

BRASIL. Lei 8.069, de 13 de julho de 1990. Disponível em: < http://www.planalto. gov.br/ccivil_03/leis/L8069.htm>. Acesso em: 13 jan. 2017.

BRASIL. Secretaria de Direitos Humanos da Presidência da República. Direito à moradia adequada. Brasília: Coordenação Geral de Educação em SDH/PR, Direitos Humanos, Secretaria Nacional de Promoção e Defesa dos Direitos Humanos, 2013. Disponível em: <http://www.sdh.gov.br/assuntos/bibliotecavirtual/promocao-edefesa/publicacoes-2013/pdfs/direito-a-moradia-adequada $>$. Acesso em: $30 \mathrm{abr}$. 2017.

BRASIL. ONUBR. Abandonadas e descartadas: mais de 150 milhões de crianças vivem nas ruas', alertam especialistas da ONU. Disponível em: < https:// nacoesunidas.org/abandonadas-e-descartadas-mais-de-150-milhoes-de-criancasvivem-nas-ruas-alertam-especialistas-da-onu/> . Acesso em: 13 dez. 2015.

CLEMENTE, Alexandre Shimizu; FREITAS, Riva Sobrado de. A dimensão humana do direito à moradia. In: ENCONTRO NACIONAL DO CONPEDI, 19., Fortaleza. Anais... Fortaleza: CONPEDI, 2010.

COHN, Clarice. Antropologia da criança. Rio de Janeiro: Zahar, 2005.

FUNDAÇÃO JOÃO PINHEIRO. Centro de Estatísticas e Informações. Déficit habitacional no Brasil 2013-2104. Belo Horizonte, 2016. Disponível em: < http:// www.fjp.mg.gov.br/index.php/docman/cei/informativos-cei-eventuais/634-deficithabitacional-06-09-2016/file> . Acesso em: 01 maio 2017.

KOHARA, Luiz. A exploração nos cortiços do Centro e a luta pelo direito de morar dignamente. In: KOWARICK, Lúcio; FRÚGOLI JR, Heitor (Org.). Pluralidade urbana em São Paulo: vulnerabilidade, marginalidade, ativismos. São Paulo: 34, FAPESP, 2016.

LABCIDADE / FAUUSP. Como fazer valer o direito das mulheres à moradia? Disponível em: <http://direitoamoradia.org/wp-content/uploads/2012/01/guiamulheres-PT.pdf> . Acesso em: 04 abr. 2016. 
LIMA, Deyseane Maria Araújo; BOMFIM, Zulmira Áurea Cruz. Vinculação afetiva pessoa-ambiente: diálogos na psicologia comunitária e psicologia ambiental. Psico, Porto Alegre, PUCRS, v. 40, n. 4, pp. 491-497, out./dez. 2009.

MILAGRES, Marcelo de Oliveira. Direito à moradia: direito especial de personalidade? 2009. 209f. Tese (Doutorado em Direito) Faculdade de Direito, Programa de PósGraduação, Universidade Federal de Minas Gerais, 2009.

PANSIERI, Flávio. Eficácia e vinculação dos direitos sociais: reflexões a partir do direito à moradia. São Paulo: Saraiva, 2012.

PAULA, Paulo Afonso Garrido de. Aula Módulo 02. Vídeo aula 1. ECA na escola, Prómenino, 1999.

ROLNIK, Raquel. Guerra dos lugares: a colonização da terra e da moradia na era das finanças. São Paulo: Boitempo, 2015.

SALATA, André Ricado; SANT'ANNA, Maria Josefina Gabriel. Entre o mercado de trabalho e a escola: os jovens no Rio de Janeiro. In: RIBEIRO, Luiz Cesar de Queiroz et al. Desigualdades urbanas, desigualdades escolares. Rio de Janeiro: Letra Capital: Observatório das Metrópoles: IPPUR/UFRJ, 2010.

SANTOS, Alessandra Figueiredo dos; MARTINEZ, Sérgio Rodrigo. Os direitos da personalidade no código civil: o conceito de vida e suas implicações ambientais. Revista Argumenta, Jacarezinho, n. 11, p. 51-73, 2009.

SARLET, Ingo Wolfgang. Algumas notas sobre a eficácia e efetividade do direito à moradia como direito de defesa aos vinte anos da Constituição Federal 1988. In: DIREITO à moradia adequada: o que é, para quem serve, como defender e efetivar. Belo Horizonte: Fórum, 2014.

SARLET, Ingo Wolfgang. O direito fundamental à moradia na Constituição: algumas anotações a respeito de seu contexto, conteúdo e possível eficácia. Revista Brasileira de Direito Público - RBDP, Belo Horizonte, ano 1, n. 02, p. 65-119, jul./set.2003.

SAULE JUNIOR, Nelson. A proteção jurídica da moradia nos assentamentos irregulares. Porto Alegre: Sergio Antonio Fabris, 2004. 
SCHREIBER, Anderson. Direitos da personalidade. 2. ed. São Paulo: Atlas, 2013.

SERRANO JÚNIOR, Odoné. $\mathrm{O}$ direito humano fundamental à moradia digna:

exigibilidade, universalização e políticas públicas para o desenvolvimento. Curitiba: Juruá, 2012.

SOUZA, Sérgio Iglesias Nunes de. Direito à moradia e de habitação:

análise comparativa e suas implicações teóricas e práticas com os direitos da personalidade. 2. ed. São Paulo: Revista dos Tribunais, 2008.

Recebido em: 15/02/2017 Aceito em: 01/11/2017 